\title{
Author Correction: Sustained perfusion of revascularized bioengineered livers heterotopically transplanted into immunosuppressed pigs
}

Mohammed F. Shaheen (D), Dong Jin Joo D, Jeffrey J. Ross D, Brett D. Anderson, Harvey S. Chen, Robert C. Huebert (D, Yi Li, Bruce Amiot, Anne Young, Viviana Zlochiver, Erek Nelson, Taofic Mounajjed, Allan B. Dietz D, Gregory Michalak, Benjamin G. Steiner, Dominique Seetapun Davidow, Christopher R. Paradise (D), Andre J. van Wijnen, Vijay H. Shah, Mengfei Liu (iD) and Scott L. Nyberg (iD)

Correction to: Nature Biomedical Engineering https://doi.org/10.1038/s41551-019-0460-x, published online 14 October 2019.

In the version of this Article originally published, the name of the author Dong Jin Joo was incorrectly listed as 'DongJin Joo'. This has now been corrected and the author initials updated accordingly in the Author contributions section.

Published online: 5 November 2019

https://doi.org/10.1038/s41551-019-0483-3

(๑) The Author(s), under exclusive licence to Springer Nature Limited 2019 